\title{
Effect of ionic liquids on the dispersion of zinc oxide and silica nanoparticles, vulcanisation behaviour and properties of NBR composites
}

\author{
M. Maciejewska*, M. Zaborski \\ Institute of Polymer and Dye Technology, Technical University of Lodz, Stefanowskiego 12/16, 90-924 Lodz, Poland
}

Received 8 May 2014; accepted in revised form 4 July 2014

\begin{abstract}
The aim of this work was to study the activity of several alkylpyrrolidinium, alkylpyridinium, alkylpiperidinium and benzylimidazolium ionic liquids (ILs) for the purpose of improving the dispersion degree of vulcanisation activator and filler nanoparticles in the acrylonitrile-butadiene elastomer (NBR). The effect of the ionic liquids on the vulcanisation kinetics of the rubber compounds, crosslink density and mechanical properties of the vulcanisates and their resistance to thermo-oxidative and UV ageing was studied.

The use of ionic liquids allowed for a homogeneous dispersion of nanoparticles in the elastomer without detrimental effects on the vulcanisation process. The physical properties and the thermal stability of the obtained vulcanisates were significantly improved. Ionic liquids increased the crosslink density of the vulcanisates and their damping properties.

Pirydinium and piperidinium hexafluorophosphates were most effective at increasing the crosslink density and improving the properties of NBR composites.
\end{abstract}

Keywords: rubber, ionic liquids, nanosized zinc oxide, silica nanoparticles, vulcanisation behaviour

\section{Introduction}

Zinc oxide is the optimal activator of sulphur vulcanisation. During vulcanisation, zinc ions react with the accelerator to form highly active zinc complexes. The crosslinking reaction is preceded by a reaction of zinc oxide with stearic acid to form hydrocarbon-soluble zinc stearate. The crosslink density increases with the concentration of zinc stearate [1]. Zinc oxide is dispersed in the elastomer in the form of crystalline particles. Particles of the accelerator, sulphur and fatty acids diffuse inside the elastomer and are adsorbed on the surface of zinc oxide to form complexes. Nieuwenhuizen [2] proposed a mechanism wherein the surface of zinc oxide participates in the reaction and is the medium of the reaction. Therefore, the dispersion of inorganic zinc oxide in an organic elastomer is the fun- damental parameter affecting the curing process. Because zinc oxide and vulcanisation accelerators are insoluble in rubber, it is assumed that crosslinking reactions occur in a two-phase system and are catalysed by conventional phase transfer catalysts, such as crown ethers or cryptands. ILs are assumed to catalyse the interfacial reactions and could function identically in the crosslinking process [3].

Despite the important role of zinc oxide in the sulphur vulcanisation of elastomers, the amount of zinc oxide in rubber compounds must be reduced to below $2.5 \%$ because of its toxicity to aquatic species [4]. Using nanosized zinc oxide as the activator is one method to reduce the amount of $\mathrm{ZnO}$ in the elastomer. Because of the reduction in particle size, this powder has a higher and more developed specific surface area. Better contact between the zinc oxide

\footnotetext{
${ }^{*}$ Corresponding author, e-mail: magdalena.maciejewska@p.lodz.pl (C) BME-PT
} 
nanoparticles and the other components of the crosslinking system is achieved, which increases the activity of $\mathrm{ZnO}$ in vulcanisation and reduces the amount used in rubber compounds [5]. The key factor is to ensure the homogeneous dispersion of the nanoparticles in the elastomer matrix. Unfortunately, zinc oxide nanoparticles reveal a high tendency to agglomerate in rubber [6] because of the high surface energy of this powder [7]. Our previous studies showed that surfactants and ionic liquids, such as alkylimidazolium salts, effectively improved the dispersion of zinc oxide nanoparticles in the elastomer [6].

Fukushima and Aida [8] reported that imidazolium ionic liquids can be used to disperse single-walled carbon nanotubes in soft composite materials. The ability of ionic liquids to functionalise and improve the dispersion of carbon nanotubes has been intensively studied $[9,10]$ also in diene elastomers [11]. Ionic liquids resulted in the development of a conductive polychloroprene rubber containing a low concentration of multi-walled carbon nanotubes (MWCNTs) $[12,13]$. The fine homogeneous dispersion of the MWCNTs and their strong secondary network in the elastomer resulted in the high conductivity of the composite. Kreyenschulte et al. [14] demonstrated attractive interactions between carbon black and ionic liquids such as 1-allyl-3-methylimidazolium chloride. It is hypothesised that these interactions are because of cation- $\pi$-interactions between IL cations and the $\pi$-electrons on the carbon black surface. ILs can act as local plasticisers at the carbon black surface and can accelerate the formation of a carbon black secondary network in unsaturated elastomers.

N-ethylmethylimidazolium bis(trifluoromethanesulfonyl)imide (EMITFSI) was used for the preparation of flexible solid polymer electrolytes based on acrylonitrile-butadiene elastomers and poly(ethylene oxide) interpenetrating polymer networks [15]. When swollen in EMITFSI, the NBR/PEO composites exhibited good mechanical properties and elongation at break and ionic conductivity higher than $10^{-4} \mathrm{~S} \cdot \mathrm{cm}^{-1}$ at room temperature. Similar results were obtained for interpenetrating polymer networks containing alkylpirrolidinium bis(trifluoromethanesulfonyl)imides [16]. Conductive NBR composites with an ionic conductivity of $2.54 \cdot 10^{-4} \mathrm{~S} \cdot \mathrm{cm}^{-1}$ have also been prepared using 1-butyl-3-methylimidazolium bis(trifluoromethyl sulfonyl)imide [17].
Ionic liquids were also used to improve the dispersion of silica in styrene-butadiene (SBR) composites. 1-Methylimidazolidine methacrylate salt (MimMa) was found to polymerise via a radical-initiated mechanism and was easily grafted onto SBR chains during vulcanisation [18]. Substantial hydrogen bonding between polymerised MimMa and silica facilitated the dispersion of silica in the elastomer and improved the interfacial interactions between SBR and silica particles. Silica agglomerates were significantly decreased, and the filler particles were uniformly distributed in the elastomer matrix. The mechanical properties of the SBR composites were improved. Similar results were reported for 1-methylimidazolium sorbate (MimS) [19]. These findings suggest that ionic liquids have the potential to improve the dispersion of solid nanoparticles in elastomers.

Our previous studies demonstrated that applying alkylimidazolium salts (bromides, chlorides, tetrafluoroborates and hexafluorophosphates) improved the dispersion of zinc oxide nanoparticles in the NBR and allowed for the production of vulcanisates with the amount of zinc oxide, sulphur and MBT reduced to $1.3 \mathrm{phr}$. These vulcanisates exhibited tensile strengths comparable to those without a dispersing agent [6]. In this work, we applied several alkylpyrrolidinium, alkylpyridinium, alkylpiperidinium and benzylimidazolium ionic liquids to improve the dispersion degree of zinc oxide and silica nanoparticles in NBR. The influence of nanosized zinc oxide and ILs on the curing kinetics of rubber compounds, vulcanisate crosslink density, tensile strength, damping properties, thermal stability and resistance to thermo-oxidative and UV ageing is discussed.

\section{Materials and methods \\ 2.1. Materials}

The acrylonitrile-butadiene elastomer (EUROPREN N3960) containing $39 \mathrm{wt} \%$ acrylonitrile was obtained from Polimeri Europa (Rome, Italy). The Mooney viscosity was $\left(\mathrm{ML} 1+4\left(100^{\circ} \mathrm{C}\right): 60\right)$. The elastomer was vulcanised with sulphur (Siarkopol, Poland), with microsized zinc oxide as the activator $(\mathrm{ZnO}$, Aldrich, USA). To reduce the amount of zinc ions in the rubber compounds, nanosized zinc oxide (nZnO, Nanostructured \& Amorphous Materials, Inc., USA) was used as an alternative to microsized $\mathrm{ZnO}$. 2-Mercaptobenzothiazole (MBT, Aldrich, USA) was used as an accelerator. Silica, with a specific surface area 
Table 1. Ionic liquids (ILs)

\begin{tabular}{|c|c|}
\hline ILs & Symbol \\
\hline 1-Ethyl-1-methylpyrrolidinium bromide & EMPYRRBr \\
\hline 1-Ethyl-1-methylpyrrolidinium hexafluorophosphate & EMPYRRPF $_{6}$ \\
\hline 1-Butyl-1-methylpyrrolidinium chloride & BMPYRRCl \\
\hline 1-Butyl-1-methylpyrrolidinium bromide & BMPYRRBr \\
\hline 1-Butyl-1-methylpyrrolidinium hexafluorophosphate & BMPYRRPF $_{6}$ \\
\hline 1-Butyl-1-methylpyrrolidinium tetrafluoroborate & $\mathrm{BMPYRRBF}_{4}$ \\
\hline 1-Benzyl-3-methylimidazolium chloride & $\mathrm{BenMICl}$ \\
\hline 1-Benzyl-3-methylimidazolium hexafluorophosphate & $\mathrm{BenMIPF}_{6}$ \\
\hline 1-Benzyl-3-methylimidazolium tetrafluoroborate & $\mathrm{BenMIBF}_{4}$ \\
\hline 1-Butyl-4-methylpyridinium chloride & BMPYRCl \\
\hline 1-Butyl-4-methylpyridinium hexafluorophosphate & BMPYRPF $_{6}$ \\
\hline 1-Butyl-4-methylpyridinium tetrafluoroborate & $\mathrm{BMPYRBF}_{4}$ \\
\hline 1-Butyl-1-methylpiperidinium hexafluorophosphate & BMPIPPF $_{6}$ \\
\hline 1-Butyl-1-methylpiperidinium tetrafluoroborate & $\mathrm{BMPIPBF}_{4}$ \\
\hline
\end{tabular}

of $380 \mathrm{~m}^{2} / \mathrm{g}$ (Aerosil 380, Evonic Industries, Germany), was used as the filler. Ionic liquids (Table 1) were obtained from Aldrich.

\subsection{Preparation and characterisation of rubber compounds}

Rubber compounds, with the formulations given in Table 2, were prepared using a laboratory two-roll mill. The samples were cured at $160^{\circ} \mathrm{C}$ until they developed a $90 \%$ increase in torque, which was measured by an oscillating disc rheometer (Monsanto). The kinetics of vulcanisation of the rubber compounds were studied using a DSC1 (Mettler Toledo) analyser by decreasing the temperature from 25 to $-60^{\circ} \mathrm{C}$ at a rate of $10^{\circ} \mathrm{C} / \mathrm{min}$ and then heating to $250^{\circ} \mathrm{C}$ at the identical heating rate. The crosslink density $\left(v_{\mathrm{T}}\right)$ of the vulcanisates was determined by their equilibrium swelling in toluene based on the Flory-Rehner equation [20]. The Huggins parameter of the elastomer-solvent interaction $(\chi)$ was calculated from the Equation (1):

$\chi=0.3809+0.6707 V_{\mathrm{r}}$

where $V_{\mathrm{r}}$ is the volume fraction of the elastomer in the swollen gel.

Table 2. Composition of the NBR-based rubber compounds [phr]

\begin{tabular}{|l|c|c|}
\hline \multicolumn{1}{|c|}{ Ingredient } & With micro-ZnO & With nano-ZnO \\
\hline NBR & 100 & 100 \\
\hline MBT & 2 & 2 \\
\hline Sulphur & 2 & 2 \\
\hline ZnO & 5 & 2 \\
\hline Silica & 30 & 30 \\
\hline Ionic liquid & - & 2 \\
\hline
\end{tabular}

The tensile properties of the vulcanisates were measured according to the standard procedures in ISO37 using a ZWICK 1435 universal testing machine. Dynamic mechanical measurements were performed in tension mode using a DMA/SDTA861e analyser (Mettler Toledo). Measurements of the dynamic moduli were performed over the temperature range of -80 to $100^{\circ} \mathrm{C}$ with a heating rate of $2^{\circ} \mathrm{C} / \mathrm{min}$, a frequency of $1 \mathrm{~Hz}$ and a strain amplitude of $4 \mu \mathrm{m}$. The elastomer glass transition temperature was determined from the maximum of $\tan \delta=f(T)$, in which $\tan \delta$ is the loss factor, and $T$ is the measurement temperature.

The thermal stability of the vulcanisates was studied using a TGA/DSC1 (Mettler Toledo) analyser. Samples were heated from 25 to $700^{\circ} \mathrm{C}$ in an argon atmosphere $(60 \mathrm{~mL} / \mathrm{min})$ with a heating rate of $10^{\circ} \mathrm{C} / \mathrm{min}$.

The thermo-oxidative degradation of the vulcanisates was performed at a temperature of $100^{\circ} \mathrm{C}$ for $240 \mathrm{~h}$. The UV degradation of the vulcanisates was performed for $120 \mathrm{~h}$ using a UV 2000 (Atlas) machine in two alternating segments: a day segment (irradiation $0.7 \mathrm{~W} / \mathrm{m}^{2}$, temperature $60^{\circ} \mathrm{C}$, time $8 \mathrm{~h}$ ) and a night segment (without UV radiation, temperature $50^{\circ} \mathrm{C}$, time $4 \mathrm{~h}$ ).

To estimate the resistance of the samples to ageing, their mechanical properties and crosslinking densities after ageing were determined and compared with the values obtained for the vulcanisates before the ageing process. The ageing factor $(S)$ was calculated as the numerical change in the mechanical properties of the samples upon ageing (Equation (2)) [21]: 
$S=\frac{(T S \cdot E B)_{\text {after ageing }}}{(T S \cdot E B)_{\text {before ageing }}}$

\section{Results and discussion}

\subsection{Dispersion of activator and filler nanoparticles in the elastomer}

The ILs were used to improve the dispersion of the vulcanisation activator (zinc oxide) and filler nanoparticles in the elastomer matrix. The homogeneous dispersion of activator particles is required to maximise the activity of the curing system in the crosslinking process. Agglomeration decreases the specific surface area of the activator and the interphase between its particles and the other components of the curing system (sulphur and accelerator). During the first step of the vulcanisation process, particles of the accelerator, sulphur and fatty acids diffuse through the elastomer matrix and are adsorbed onto the $\mathrm{ZnO}$ surface, forming intermediate reactive complexes [1]. Therefore, the contact between the $\mathrm{ZnO}$ particles and the accelerator in the elastomer matrix should be maximised to enhance the efficiency of the zinc oxide during vulcanisation. The dispersion of the filler particles controls the reinforcement effect of the filler and determines the mechanical properties of the vulcanisate. Agglomerates concentrate stresses in the material when subjected to external strain that can lead to early destruction. SEM images of the vulcanisate surfaces were obtained to examine the dispersion of the activator and filler nanoparticles in the elastomer. These results are presented in Figure $1 \mathrm{a}-1 \mathrm{j}$.

Zinc oxide and silica nanoparticles showed a strong tendency to agglomerate in the elastomer. They formed agglomerates several micrometres in size consisting of nanosized primary particles (Figure 1a). The dispersion of the zinc oxide and filler particles in the presence of ILs is presented in Figures $1 \mathrm{~b}-1 \mathrm{j}$. Hexafluorophosphates and tetrafluoroborates significantly improved the dispersion of the nanoparticles in the elastomer. The particles were homogeneously dispersed and tightly bound to the elastomer matrix. Therefore, these salts seem to be active dispersing agents that can improve the dispersion degree of zinc oxide and silica in the NBR elastomer. Chlorides were less effective in preventing the particles from agglomeration. Nanoparticles created small agglomerates approximately $1-2 \mu \mathrm{m}$ in size. However, these agglomerates were uni- formly dispersed in the elastomer and were surrounded with elastomer film. They did not affect the tensile properties of the vulcanisates. The lower efficiency of the chlorides can be related to their poor miscibility with the elastomer during the preparation of the rubber compounds. The addition of these ILs resulted in the crumbling of the elastomer during processing with the use of the two-roll mill.

\subsection{Curing characteristics and the crosslink density of the vulcanisates}

The influence of ILs on the vulcanisation process was estimated based on rheometer measurements. The curing characteristics of the NBR compounds and the crosslink densities of the vulcanisates are given in Table 3.

For curing, the conventional NBR compound system consisting of an accelerator (MBT), sulphur and microsized zinc oxide was used and compared with the system containing nanosized zinc oxide and IL. The use of nanosized zinc oxide increased the torque increment compared with that of the reference rubber compound containing microsized $\mathrm{ZnO}$. No considerable influence on the vulcanisation time or scorch time was observed. The use of the ILs significantly reduced the vulcanisation time and increased the torque increment of the rubber compounds compared to the reference compounds with micro- or nanosized zinc oxide. The crosslink density of the

Table 3. Curing characteristics and crosslink densities of NBR vulcanisates containing ILs

\begin{tabular}{|c|c|c|c|c|}
\hline ILs & $\begin{array}{c}\Delta G \\
{[d N m]}\end{array}$ & $\begin{array}{c}\mathrm{t}_{90} \\
{[\mathrm{~min}]}\end{array}$ & $\begin{array}{c}\mathbf{t}_{\mathrm{p}} \\
{[\mathrm{min}]}\end{array}$ & $\begin{array}{c}\mathbf{v}_{\mathrm{T} \cdot 10^{4}} \\
{\left[\mathrm{~mol} / \mathrm{cm}^{3}\right]}\end{array}$ \\
\hline $\mathrm{ZnO}$ & 44.5 & 50 & 2.2 & 19.8 \\
\hline $\mathrm{nZnO}$ & 67.8 & 50 & 2.9 & 20.4 \\
\hline EMPYRRBr & 123.2 & 40 & 2.1 & 22.5 \\
\hline EMPYRRPF $_{6}$ & 106.5 & 45 & 3.1 & 21.9 \\
\hline BMPYRRCl & 120.5 & 25 & 2.8 & 23.1 \\
\hline BMPYRRBr & 109.2 & 25 & 2.9 & 21.3 \\
\hline $\mathrm{BMPYRRPF}_{6}$ & 101.5 & 40 & 3.6 & 21.2 \\
\hline $\mathrm{BMPYRRBF}_{4}$ & 97.4 & 30 & 3.6 & 20.1 \\
\hline BenMICl & 109.0 & 30 & 3.1 & 21.4 \\
\hline BenMIPF $_{6}$ & 102.3 & 37 & 3.0 & 20.8 \\
\hline $\mathrm{BenMIBF}_{4}$ & 104.0 & 35 & 2.7 & 20.3 \\
\hline BMPYRCl & 104.3 & 22 & 2.5 & 23.6 \\
\hline $\mathrm{BMPYRPF}_{6}$ & 104.7 & 40 & 3.5 & 21.7 \\
\hline $\mathrm{BMPYRBF}_{4}$ & 109.9 & 40 & 3.5 & 20.4 \\
\hline BMPIPPF6 & 111.0 & 45 & 3.5 & 21.5 \\
\hline BMPIPBF4 & 114.4 & 45 & 2.5 & 21.1 \\
\hline
\end{tabular}

$\Delta G$ - increment of torque in the rubber compound during vulcanisation; $t_{90}-$ optimal vulcanisation time; $t_{\mathrm{p}}-$ scorch time, $v_{\mathrm{T}}-$ crosslink density of vulcanisates 


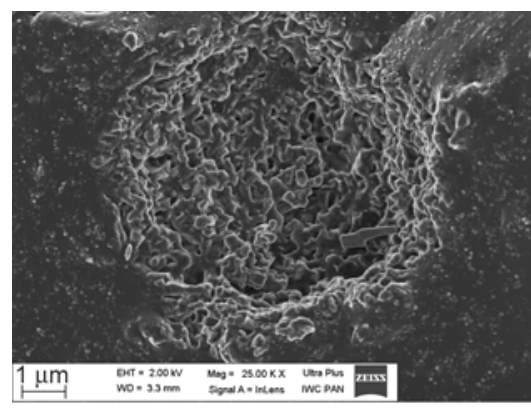

a)

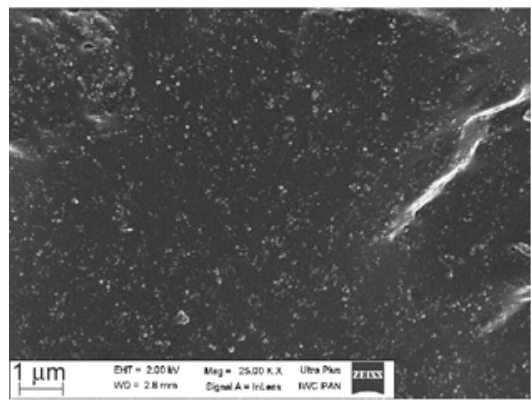

d)

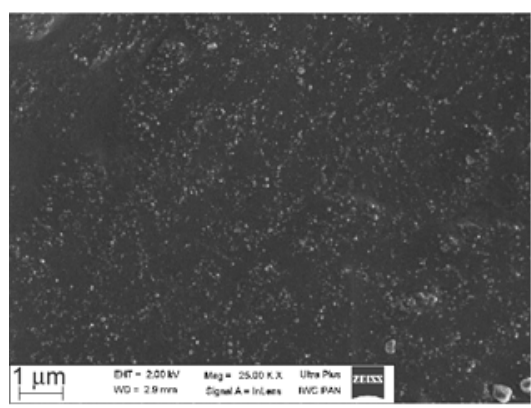

g)

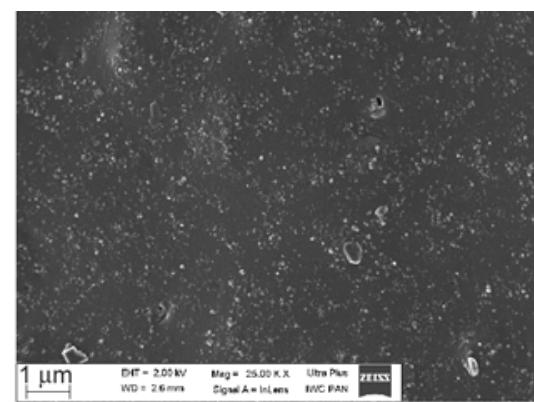

b)

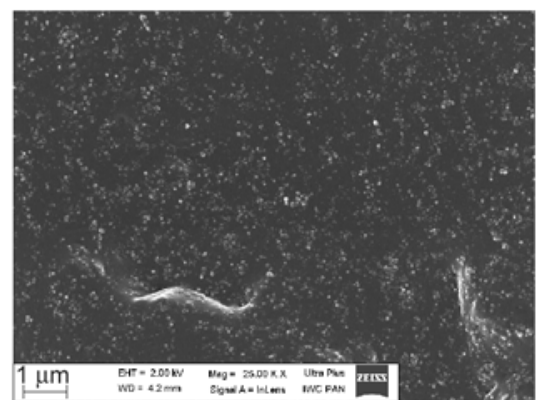

e)

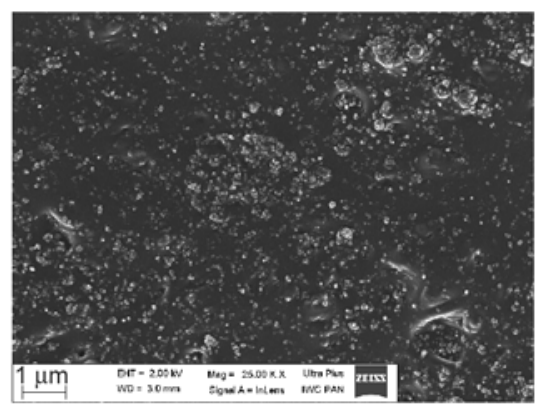

h)

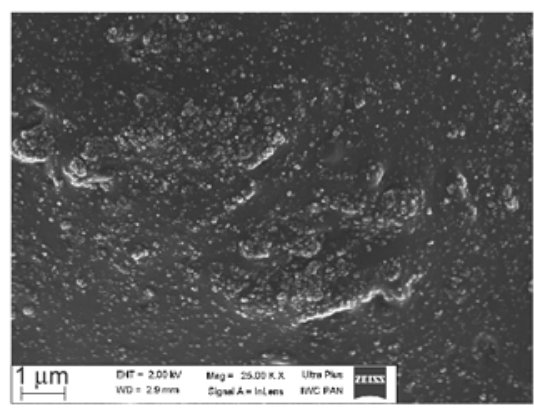

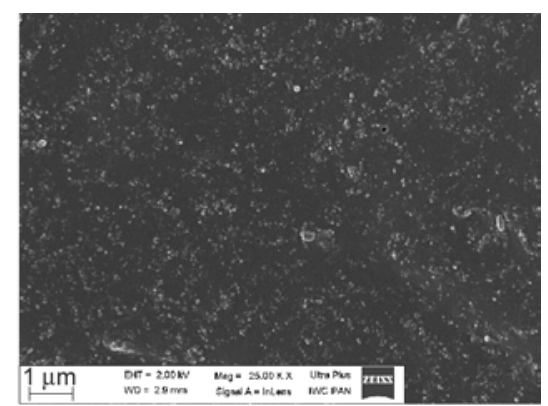

c)

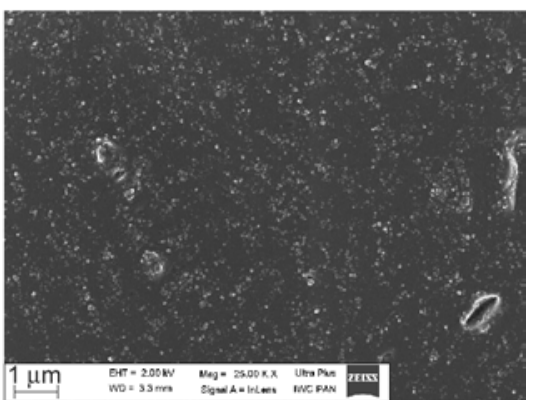

f)

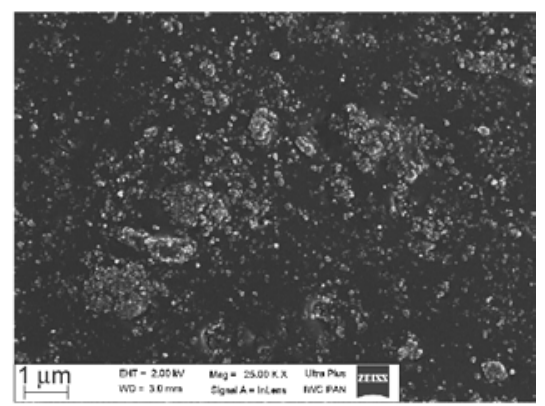

i)

j)

Figure 1. SEM images of vulcanisates: a) without IL, b) with $\mathrm{EMPYRRPF}_{6}$, c) with $\mathrm{BMPYRRPF}_{6}$, d) with $\mathrm{BenMIBF}_{4}$, e) with $\mathrm{BMPYRPF}_{6}$, f) with $\mathrm{BMPYRBF}_{4}$, g) $\mathrm{BMPIPPF}_{6}$, h) with BMPYRRCl, i) with BenMICl, j) with BMPYRCl

vulcanisates also increased. This increase could be because of the more homogeneous dispersion of the zinc oxide nanoparticles in the elastomer that led to better contact between particles of the vulcanisation activator and the other components of the curing system (sulphur, accelerator). ILs may have acted as a catalyst for the interfacial crosslinking reactions. Zinc oxide and vulcanisation accelerators are insoluble in the rubber. Therefore, the crosslinking reac- tions occur in a two-phase system. ILs are presumed to catalyse the interfacial reactions [3]. This assumption is confirmed by the fact that the composites containing chlorides were characterised by the shortest vulcanisation time and higher crosslink density compared to other ILs, despite poor dispersion of zinc oxide nanoparticles (Figures $1 \mathrm{~b}-1 \mathrm{j}$ ).

There was no simple correlation between the structure of the IL and its influence on the curing charac- 
Table 4. Temperature and energetic effects of NBR vulcanisation measured by DSC

\begin{tabular}{|l|c|c|}
\hline \multicolumn{1}{|c|}{ ILs } & $\begin{array}{c}\text { Vulcanisation } \\
\text { temperature range } \\
{\left[{ }^{\circ} \mathbf{C}\right]}\end{array}$ & $\begin{array}{c}\text { Energetic effect of } \\
\text { vulcanisation } \\
{[\mathbf{J} / \mathbf{g}]}\end{array}$ \\
\hline $\mathrm{ZnO}$ & $163-240$ & 10.1 \\
\hline $\mathrm{nZnO}$ & $165-240$ & 10.3 \\
\hline EMPYRRPF $_{6}$ & $168-244$ & 17.6 \\
\hline $\mathrm{BMPYRRCl}$ & $143-230$ & 9.5 \\
\hline $\mathrm{BMPYRRBr}$ & $140-230$ & 8.3 \\
\hline BMPYRRPF $_{6}$ & $168-240$ & 12.6 \\
\hline BMPYRRBF $_{4}$ & $145-230$ & 9.5 \\
\hline BenMIPF $_{6}$ & $168-237$ & 13.2 \\
\hline $\mathrm{BMPYRPF}_{6}$ & $168-230$ & 10.6 \\
\hline $\mathrm{BMPIPPF}_{6}$ & $168-236$ & 10.9 \\
\hline
\end{tabular}

teristics. However, vulcanisates containing pyrrolidinium salts exhibited one of the highest crosslink densities.

We then examined the influence of nanosized zinc oxide and ILs on the temperature and energetic effects of vulcanisation using DSC analysis. The results for exemplary rubber compounds are given in Table 4.

Nanosized zinc oxide had no significant influence on the temperature and heat of vulcanisation compared with those of the NBR compounds containing the microsized activator. The vulcanisation is an exothermic process that took place in a temperature range of $163-240^{\circ} \mathrm{C}$, with an energetic effect of $10 \mathrm{~J} / \mathrm{g}$. The hexafluorophosphates did not affect the vulcanisation temperature, but the increase in the energetic effect of the process was observed in most of the rubber compounds. Chlorides, bromides and tetrafluoroborates, regardless of the cation type, decreased the vulcanisation onset temperature by $20^{\circ} \mathrm{C}$ compared with rubber compounds with micro- or nanosized zinc oxide. The application of these ILs allows the NBR elastomer to be cured at lower temperatures than the commonly used $160^{\circ} \mathrm{C}$.

\subsection{Mechanical properties of the vulcanisates}

The aim of applying the ILs was to achieve the homogeneous dispersion of the zinc oxide and silica nanoparticles in the elastomer and to improve the tensile strength of the vulcanisates. The mechanical properties of the NBR vulcanisates were studied under static and dynamic conditions. The results of the tensile tests are presented in Table 5.

NBR conventionally crosslinked with sulphur exhibited a tensile strength of $20.4 \mathrm{MPa}$ and an elongation at break of approximately $531 \%$. Nanosized zinc
Table 5. Mechanical properties of NBR vulcanisates containing ILs

\begin{tabular}{|l|c|c|}
\hline \multicolumn{1}{|c|}{ ILs } & $\begin{array}{c}\text { TS } \\
{[\mathbf{M P a}]}\end{array}$ & $\begin{array}{c}\text { EB } \\
{[\mathbf{\%}]}\end{array}$ \\
\hline $\mathrm{ZnO}$ & 20.4 & 531 \\
\hline $\mathrm{nZnO}$ & 22.4 & 526 \\
\hline EMPYRRBr & 26.6 & 435 \\
\hline EMPYRRPF $_{6}$ & 26.3 & 490 \\
\hline BMPYRRCl & 23.8 & 429 \\
\hline BMPYRRBr $_{\text {BMPYRRPF }_{6}}$ & 23.7 & 411 \\
\hline BMPYRRBF $_{4}$ & 27.0 & 502 \\
\hline BenMICl & 25.0 & 520 \\
\hline BenMIPF $_{6}$ & 23.4 & 425 \\
\hline BenMIBF $_{4}$ & 25.8 & 501 \\
\hline BMPYRCl & 27.3 & 530 \\
\hline BMPYRPF $_{6}$ & 24.7 & 402 \\
\hline BMPYRBF $_{4}$ & 26.8 & 465 \\
\hline BMPIPPF $_{6}$ & 27.0 & 520 \\
\hline BMPIPBF $_{4}$ & 26.4 & 430 \\
\hline
\end{tabular}

$T S$ - tensile strength; $E B$ - elongation at break.

oxide increased the tensile strength by $2 \mathrm{MPa}$, whereas the elongation at break did not change. The ILs increased the tensile strength of the vulcanisates by 2-5 MPa compared with the vulcanisate containing only nanosized zinc oxide. The elongation at break was reduced for vulcanisates with a higher crosslink density than that of the reference nZnOcontaining vulcanisate. The highest tensile strength was achieved for vulcanisates with pyridinium hexafluorophosphate and tetrafluoroborate and pyrrolidinium hexafluorophosphate and bromide.

The dynamic mechanical properties are important for the application of rubber products. The rigidity and strength of vulcanisates should be stable and the material must be able to dampen vibration. The influence of ILs on the loss factor $(\tan \delta)$ was determined with DMA. The loss factor $\tan \delta$ as a function of temperature for the vulcanisates containing ILs is presented in Figure 2. The presence of one transition can be observed. This is the glass transition of the NBR elastomer, with a maximum that represents the glass transition temperature $T_{\mathrm{g}}$.

The values of the glass transition temperature and the loss factor at $T_{\mathrm{g}}$, room temperature and an elevated temperature $\left(100^{\circ} \mathrm{C}\right)$ are compiled in Table 6 . The glass transition temperature of NBR containing the standard activator - microsized zinc oxide - was $-7.3^{\circ} \mathrm{C}$. Applying nanosized zinc oxide increased the glass transition temperature of the elastomer because of the higher crosslink density of the vulcanisate. The ILs caused a further small increase in the $T_{\mathrm{g}}$ of 


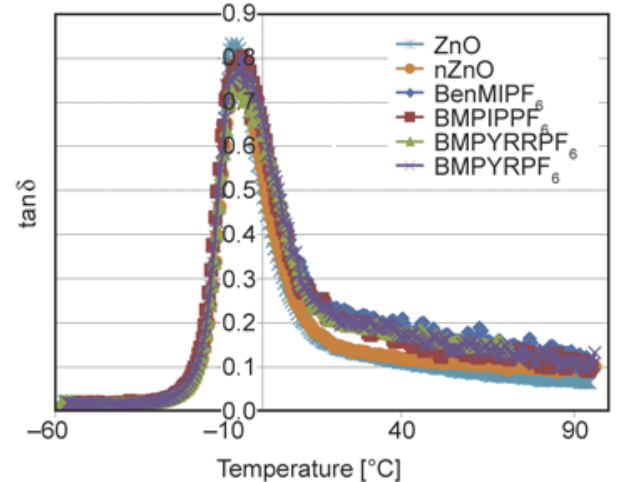

Figure 2. Loss factor $(\tan \delta)$ versus temperature for NBR vulcanisates containing ILs

Table 6. Glass transition temperature and loss factor of NBR vulcanisates containing ILs

\begin{tabular}{|l|c|c|c|c|}
\hline \multicolumn{1}{|c|}{ ILs } & $\begin{array}{c}\mathbf{T}_{\mathbf{g}} \\
{\left[{ }^{\circ} \mathbf{C}\right]}\end{array}$ & $\begin{array}{c}\tan \boldsymbol{\delta} \text { at } \mathbf{T}_{\mathbf{g}} \\
{[-]}\end{array}$ & $\begin{array}{c}\tan \boldsymbol{\delta} \text { at } 25^{\circ} \mathbf{C} \\
{[-]}\end{array}$ & $\begin{array}{c}\tan \boldsymbol{\delta} \text { at } 100^{\circ} \mathbf{C} \\
{[-]}\end{array}$ \\
\hline $\mathrm{ZnO}$ & -7.3 & 0.58 & 0.11 & 0.06 \\
\hline nZnO & -6.5 & 0.69 & 0.13 & 0.10 \\
\hline BMPYRRPF $_{6}$ & -5.7 & 0.78 & 0.14 & 0.10 \\
\hline BenMIPF $_{6}$ & -5.2 & 0.77 & 0.22 & 0.11 \\
\hline BMPYRPF $_{6}$ & -6.2 & 0.80 & 0.20 & 0.11 \\
\hline BMPIPPF $_{6}$ & -6.0 & 0.80 & 0.20 & 0.10 \\
\hline
\end{tabular}

$T_{\mathrm{g}}-$ glass transition temperature; $\tan \delta-$ loss factor.

the vulcanisates, which was the result of the crosslinked elastomer network that formed during vulcanisation and restricted the mobility of the elastomer chains. The nanosized zinc oxide and the ILs increased the loss factor at $T_{\mathrm{g}}$, room and elevated temperatures. It is hypothesised that these vulcanisates would demonstrate better damping properties at the examined temperatures.

\subsection{Thermal stability and ageing resistance of vulcanisates}

Thermal stability and ageing resistance are important properties of rubber products for technological applications. ILs are used to improve the dispersion degree of zinc oxide and silica in the elastomer should not deteriorate these properties. The thermal stability of the vulcanisates was based on the decomposition temperature and total weight loss of the sample determined by TGA analysis. The results are presented in Table 7.

The thermal decomposition of the vulcanisate containing microsized zinc oxide began at $300^{\circ} \mathrm{C}$. Replacing the standard activator with nanosized zinc oxide significantly improved the thermal stability of NBR. The decomposition of the vulcanisate started at a temperature that was $50^{\circ} \mathrm{C}$ higher than that of
Table 7. Decomposition temperatures at a weight loss of $2 \%$ $\left(T_{02}\right), 5 \%\left(T_{05}\right)$, and $50 \%\left(T_{50}\right)$ and the total weight loss during decomposition of NBR vulcanisates containing ILs

\begin{tabular}{|l|c|c|c|c|}
\hline \multicolumn{1}{|c|}{ ILs } & $\begin{array}{c}\mathbf{T}_{\mathbf{0 2}} \\
{\left[{ }^{\circ} \mathbf{C}\right]}\end{array}$ & $\begin{array}{c}\mathbf{T}_{\mathbf{0 5}} \\
{\left[{ }^{\circ} \mathbf{C}\right]}\end{array}$ & $\begin{array}{c}\mathbf{T}_{\mathbf{5 0}} \\
{\left[{ }^{\circ} \mathbf{C}\right]}\end{array}$ & $\begin{array}{c}\text { Total weight loss } \\
{[\mathbf{\%}]}\end{array}$ \\
\hline $\mathrm{ZnO}$ & 300 & 368 & 446 & 68.5 \\
\hline nZnO & 350 & 377 & 458 & 70.6 \\
\hline EMPYRRPF $_{6}$ & 372 & 394 & 465 & 68.8 \\
\hline BMPYRRPF $_{6}$ & 370 & 392 & 465 & 68.9 \\
\hline BenMIPF $_{6}$ & 370 & 390 & 465 & 68.9 \\
\hline BMPYRPF $_{6}$ & 372 & 393 & 465 & 69.0 \\
\hline BMPIPPF $_{6}$ & 369 & 391 & 464 & 69.0 \\
\hline
\end{tabular}

the reference vulcanisate. The use of ILs caused a further increase in the thermal stability of NBR, possibly because of the homogeneous dispersion of the nanoparticles in the elastomer matrix. The network created by the filler particles may be a barrier for the transport of gases and volatile pyrolysis products, thus increasing the thermal stability of the material. ILs also increased the temperatures at 5 and $50 \%$ weight loss. The $5 \%$ weight loss was achieved at the temperature range of $390-394^{\circ} \mathrm{C}$, and $50 \%$ weight loss occurred at $464-465^{\circ} \mathrm{C}$. The total weight loss during decomposition was similar for all vulcanisates $(68.5-70.6 \%)$.

After establishing the effects of nanosized zinc oxide and ILs on the thermal stability, we then examined the vulcanisates' resistance to thermo-oxidative and UV ageing. The effect of ILs on ageing resistance was studied through the changes in the mechanical properties and the crosslink density of the vulcanisates. In Figure 3, the change in crosslink density upon thermo-oxidative and UV ageing is reported for the vulcanisates containing hexafluorophosphates. The ageing process increased the crosslink density of the vulcanisates. This effect was particularly evident in the case of thermo-oxidative ageing. The increase

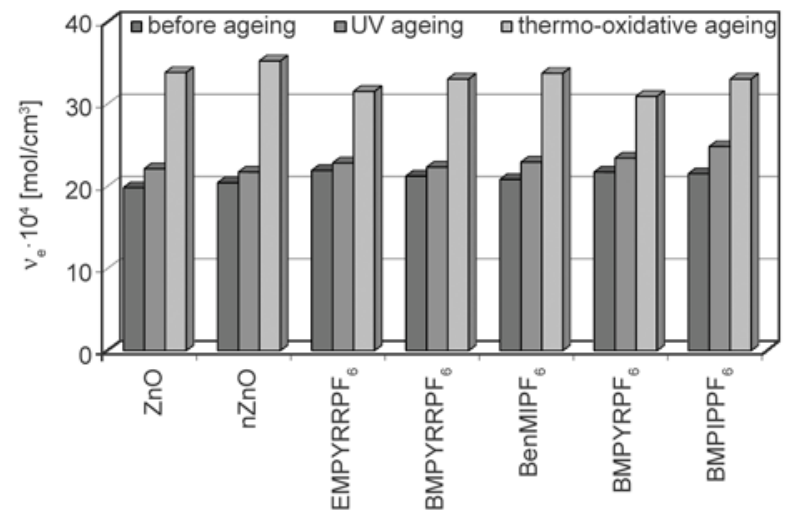

Figure 3. Vulcanisate crosslink density after ageing 


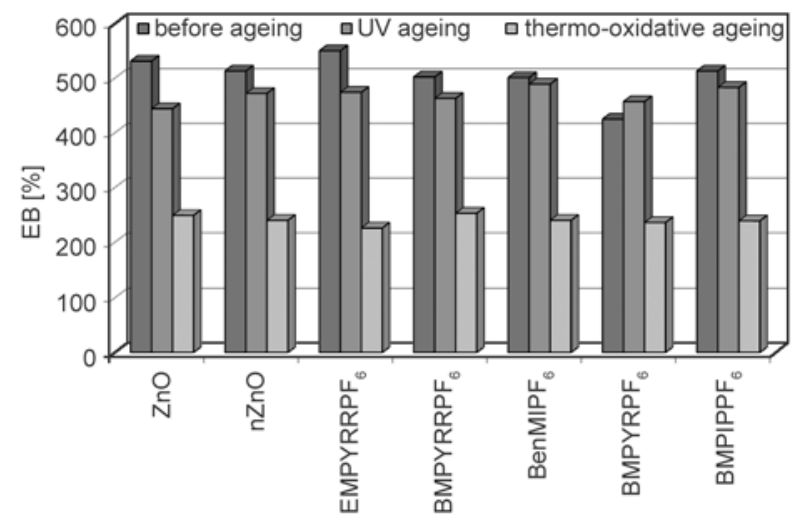

Figure 4. Vulcanisate elongation at break after ageing

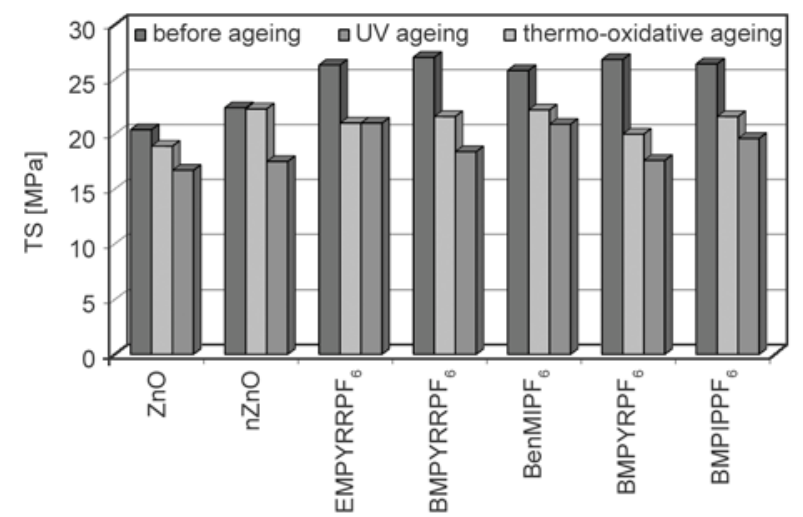

Figure 5. Vulcanisate tensile strength after ageing

in crosslink density resulted in the reduction of the vulcanisates' elongation at break (approximately $300 \%$ for thermo-oxidative ageing) (Figure 4.) The vulcanisates became more rigid and brittle, corresponding to a reduction of their tensile strength (Figure 5).

It was difficult to estimate the resistance of the vulcanisates to the ageing process using changes in tensile strength and the elongation at break separately. Therefore, the ageing factor $S$ was calculated to quantitatively estimate the change in the mechanical properties of the vulcanisates (Table 8 ). The ageing factor could be defined as the change in the deformation energy of the material as a result of the ageing process.

The nanosized zinc oxide and the ILs had no considerable influence on the vulcanisates' resistance to thermo-oxidative and UV ageing. A small improvement in the UV ageing resistance was observed for BMPYRCl and BMPIPBF 4 . The $S_{\mathrm{UV}}$ values are significantly higher than the $S_{\mathrm{T}}$ values, indicating that prolonged exposure to elevated temperature is more
Table 8. Thermo-oxidative and UV ageing factors for NBR vulcanisates containing ILs

\begin{tabular}{|c|c|c|}
\hline ILs & $\begin{array}{l}\mathbf{S}_{\mathbf{T}} \\
{[-]}\end{array}$ & $\begin{array}{c}\mathbf{S}_{\mathbf{U V}} \\
{[-]}\end{array}$ \\
\hline $\mathrm{ZnO}$ & 0.43 & 0.68 \\
\hline $\mathrm{nZnO}$ & 0.47 & 0.72 \\
\hline EMPYRRBr & 0.39 & 0.65 \\
\hline EMPYRRPF $_{6}$ & 0.38 & 0.66 \\
\hline BMPYRRCl & 0.43 & 0.59 \\
\hline BMPYRRBr & 0.41 & 0.78 \\
\hline $\mathrm{BMPYRRPF}_{6}$ & 0.40 & 0.73 \\
\hline $\mathrm{BMPYRRBF}_{4}$ & 0.38 & 0.65 \\
\hline BenMICl & 0.49 & 0.72 \\
\hline BenMIPF $_{6}$ & 0.41 & 0.79 \\
\hline $\mathrm{BenMIBF}_{4}$ & 0.41 & 0.59 \\
\hline BMPYRCl & 0.46 & 0.81 \\
\hline BMPYRPF $_{6}$ & 0.41 & 0.71 \\
\hline $\mathrm{BMPYRBF}_{4}$ & 0.42 & 0.69 \\
\hline BMPIPPF $_{6}$ & 0.38 & 0.70 \\
\hline $\mathrm{BMPIPBF}_{4}$ & 0.41 & 0.82 \\
\hline
\end{tabular}

$S_{\mathrm{T}}$ - thermo-oxidative ageing factor; $S_{\mathrm{UV}}-\mathrm{UV}$ ageing factor.

destructive to material properties than UV radiation.

\section{Conclusions}

Ionic liquids (alkylpyrrolidinium, alkylpyridinium, alkylpiperidinium and benzylimidazolium salts) were used to improve the dispersion degree of a nanosized vulcanisation activator (zinc oxide) and filler (silica). The use of ILs allowed for the homogeneous dispersion of nanoparticles in the elastomer matrix and resulted in the shortening of the optimal vulcanisation time. Chlorides, bromides and tetrafluoroborates decreased the vulcanisation onset temperature by $20^{\circ} \mathrm{C}$. ILs increased the vulcanisates' tensile strength compared with the vulcanisate that contained only nanosized zinc oxide. IL-containing vulcanisates also demonstrated better thermal stability and damping properties at the usage temperature. ILs did not affect the resistance of the vulcanisates to thermo-oxidative and UV ageing.

Using nanosized zinc oxide with ILs reduced the amount of zinc ions by $60 \%$ compared with conventional rubber compounds containing $5 \mathrm{phr}$ of microsized $\mathrm{ZnO}$ as is required by the European Union legislation.

\section{Acknowledgements}

The authors wish to acknowledge the National Centre for Research and Development for supporting this research. 


\section{References}

[1] Nieuwenhuizen P. J., van Veen J. M., Haasnoot J. G., Reedijk J.: Homogeneous zinc(II) catalysis in accelerated vulcanization IV. The Mechanism of cross-link (de)sulfuration. Rubber Chemistry and Technology, 72, 43-54 (1999).

DOI: $10.5254 / 1.3538793$

[2] Nieuwenhuizen P. J.: Zinc accelerator complexes.: Versatile homogeneous catalysts in sulfur vulcanization. Applied Catalysis A: General, 207, 55-68 (2001). DOI: 10.1016/S0926-860X(00)00613-X

[3] Lu J., Yan F., Texter J.: Advanced applications of ionic liquids in polymer science. Progress in Polymer Science, 34, 431-448 (2009).

DOI: 10.1016/j.progpolymsci.2008.12.001

[4] Chapman A., Johnson T.: The role of zinc in the vulcanisation of styrene-butadiene rubbers. Kautschuk und Gummi Kunststoffe, 58, 358-361 (2005).

[5] Przybyszewska M., Zaborski M.: The vulcanizates containing a reduced amount of zinc oxide. Przemysl Chemiczny, 85, 976-978 (2006).

[6] Przybyszewska M., Zaborski M.: Effect of ionic liquids and surfactants on zinc oxide nanoparticle activity in crosslinking of acrylonitrile butadiene elastomer. Journal of Applied Polymer Science, 116, 155-164 (2010).

DOI: 10.1002/app.31519

[7] Przybyszewska M., Krzywania A., Zaborski M., Szynkowska M. I.: Surface properties of zinc oxide nanoparticles studied by inverse gas chromatography. Journal of Chromatography A, 1216, 5284-5291 (2009).

DOI: $10.1016 /$ j.chroma.2009.04.094

[8] Fukushima T., Aida T.: Ionic liquids for soft functional materials with carbon nanotubes. Chemistry - A European Journal, 13, 5048-5058 (2007).

DOI: $10.1002 /$ chem.200700554

[9] Ma P-C., Siddiqui N. A., Marom G., Kim J-K.: Dispersion and functionalization of carbon nanotubes for polymer-based nanocomposites: A review. Composites Part A: Applied Science and Manufacturing, 41, 1345-1367 (2010).

DOI: 10.1016/j.compositesa.2010.07.003

[10] Jiang M-J., Dang Z-M., Xu H-P.: Significant temperature and pressure sensitivities of electrical properties in chemically modified multiwall carbon nanotube/ methylvinyl silicone rubber nanocomposites. Applied Physics Letters, 89, 182902/1-182902/2 (2006). DOI: $10.1063 / 1.2369643$

[11] Das A., Stöckelhuber K. W., Jurk R., Fritzsche J., Klüppel M., Heinrich G.: Coupling activity of ionic liquids between diene elastomers and multi-walled carbon nanotubes. Carbon, 47, 3313-3321 (2009).

DOI: $10.1016 /$ j.carbon.2009.07.052
[12] Subramaniam K., Das A., Heinrich G.: Development of conducting polychloroprene rubber using imidazolium based ionic liquid modified multi-walled carbon nanotubes. Composites Science and Technology, 71, 1441-1449 (2011). DOI: $10.1016 /$ j.compscitech.2011.05.018

[13] Steinhauser D., Subramaniam K., Das A., Heinrich G., Klüppel M.: Influence of ionic liquids on the dielectric relaxation behavior of CNT based elastomer nanocomposites. Express Polymer Letters, 6, 927-936 (2012). DOI: 10.3144/expresspolymlett.2012.98

[14] Kreyenschulte H., Richter S., Götze T., Fischer D., Steinhauser D., Klüppel M., Heinrich G.: Interaction of 1-allyl-3-methyl-imidazolium chloride and carbon black and its influence on carbon black filled rubbers. Carbon, 50, 3649-3658 (2012).

DOI: $10.1016 /$ j.carbon.2012.03.037

[15] Goujon L. J., Khaldi A., Maziz A., Plesse C., Nguyen G. T. M., Aubert P-H., Vidal F., Chevrot C., Teyssié D.: Flexible solid polymer electrolytes based on nitrile butadiene rubber/poly(ethylene oxide) interpenetrating polymer networks containing either LiTFSI or EMITFSI. Macromolecules, 44, 9683-9691 (2011). DOI: $10.1021 / \mathrm{ma} 201662 \mathrm{~h}$

[16] Shaplov A. S., Ponkratov D. O., Vlasov P. S., Lozinskaya E. I., Malyshkina I. A., Vidal F., Aubert P-H., Armand M., Vygodskii Y. S.: Solid-state electrolytes based on ionic network polymers. Polymer Science Series B, 56, 164-177 (2014). DOI: $10.1134 / \mathrm{S} 1560090414020134$

[17] Marwanta E., Mizumo T., Nakamura N., Ohno H.: Improved ionic conductivity of nitrile rubber/ionic liquid composites. Polymer, 46, 3795-3800 (2005). DOI: $10.1016 /$ j.polymer.2005.02.113

[18] Lei Y. D., Tang Z. H., Guo B. C., Zhu L. X., Jia D. M.: Synthesis of novel functional liquid and its application as a modifier in SBR/silica composites. Express Polymer Letters, 4, 692-703 (2010).

DOI: $10.3144 /$ expresspolymlett.2010.84

[19] Guo B., Chen F., Lei Y., Liu X., Wan J., Jia D.: Styrene-butadiene rubber/halloysite nanotubes nanocomposites modified by sorbic acid. Applied Surface Science, 255, 7329-7336 (2009).

DOI: $10.1016 / \mathrm{j}$. apsusc.2009.03.092

[20] Flory P. J., Rehner J.: Statistical mechanics of crosslinked polymer networks II. Swelling. Journal of Chemical Physics, 11, 521-526 (1943). DOI: $10.1063 / 1.1723792$

[21] Masek A., Zaborski M., Kosmalska A.: Derivatives of flavonoides as anti-ageing substances in elastomers. Comptes Rendus Chimie, 14, 483-488 (2011). DOI: $10.1016 /$ j.crci.2011.01.001 